\title{
Time varying price discovery
}

Article

Accepted Version

Avino, D., Lazar, E. and Varotto, S. (2015) Time varying price discovery. Economics Letters, 126. pp. 18-21. ISSN 01651765 doi: https://doi.org/10.1016/j.econlet.2014.09.030 Available at https://centaur.reading.ac.uk/40373/

It is advisable to refer to the publisher's version if you intend to cite from the work. See Guidance on citing.

To link to this article DOI: http://dx.doi.org/10.1016/j.econlet.2014.09.030

Publisher: Elsevier

All outputs in CentAUR are protected by Intellectual Property Rights law, including copyright law. Copyright and IPR is retained by the creators or other copyright holders. Terms and conditions for use of this material are defined in the End User Agreement.

\section{www.reading.ac.uk/centaur}

\section{CentAUR}

Central Archive at the University of Reading

Reading's research outputs online 


\title{
Time Varying Price Discovery
}

\author{
Davide Avino $^{\mathrm{a}}$, Emese Lazar ${ }^{\mathrm{b}}$, Simone Varotto $^{\mathrm{b}}$
}

Current version: October 2013

\begin{abstract}
We show how multivariate GARCH models can be used to generate a time-varying "information share" (Hasbrouck, 1995) to represent the changing patterns of price discovery in closely related securities. As an application we look at the credit spreads obtained from the credit default swap (CDS), bond, equity and option markets. Using data on Marks \& Spencer Plc we find evidence of substantial time variation in the contributions of the different markets to the price discovery of credit risk. We also show how a time-varying information share can improve credit spread predictions.
\end{abstract}

JEL classification: G01; G14

Keywords: credit spreads; price discovery; multivariate GARCH

* Contact: davide.avino@ucd.ie (D. Avino), e.lazar@icmacentre.ac.uk (E. Lazar) and s.varotto@icmacentre.ac.uk (S. Varotto). a Department of Banking and Finance, Smurfit Graduate School of Business, University College Dublin, Carysfort Avenue, Blackrock, Dublin, Ireland.

b ICMA Centre, Henley Business School, University of Reading, Reading, RG6 6BA, United Kingdom. 


\section{Introduction}

In this paper we contribute to the existing literature on price discovery, which looks at the incorporation of new information in closely linked securities trading in different markets, by proposing a time varying version of a standard price discovery measure. This is ideally suited to capture the fast changing roles of these markets in the price formation process, especially in periods characterised by high uncertainty. Specifically, we look at the time varying price discovery of credit spreads obtained from the CDS, bond, equity and option markets. Previous studies in this area show that changes in the price discovery mechanism are rather common. Zhu (2004), Blanco et al. (2005) and Bai and Collin-Dufresne (2011) find that the CDS market leads the bond market. However, during the financial crisis of 2008 the price discovery occurring in the CDS market reduces significantly while it increases for the bond market (see Bai and CollinDufresne, 2011). By looking at stock returns (or stock implied spreads) alongside CDS and bond spreads, Longstaff et al. (2003), Norden and Weber (2009) and Forte and Peña (2009) find equities and CDSs to lead the bond market. In the latter study as well as in Avino et al. (2013), who further extend the analysis to include option implied credit spreads, such time variations are also explicitly documented. However, the approach taken so far to highlight time dependence is to estimate and compare price discovery measures in sub-periods of the original sample. We argue that this practice has limited applicability as the sub-periods need to be sufficiently long as to ensure robust estimates. This constrains the frequency with which time variations can be reliably measured.

All the above studies employ either a VAR or VECM as the basis to quantify the price discovery that takes place in each market. ${ }^{1}$ With a VECM the percentage of price discovery which occurs in each market for a specific estimation period can be estimated with the "information share" (IS) of Hasbrouck (1995). (See for example, Blanco et al., 2005; Forte and Peña, 2009). ${ }^{2}$ One limitation of this approach is that the price discovery obtained for each market is fixed during the period under study. In this paper we show how a time-varying estimate of the IS measure can be

\footnotetext{
${ }^{1}$ Acharya and Johnson (2007) and Berndt and Ostrovnaya (2008) also study the information flow between CDS and equity markets and CDS, equity and option markets, respectively. By using panel regressions long run equilibrium relationships that may exist among the spreads implied from the different markets, cannot be taken into account.

2 The information share of a market can be interpreted as the proportion of the variance of the common factor explained by that market. The higher the proportion, the closer the market to the efficient price, and the more dominant its role in price discovery.
} 
obtained by applying GARCH models to the VECM innovations, if a long run equilibrium relationship exists between the different markets. We also show a simple way in which the forecasting ability of the VECM can be improved using a time-varying price discovery measure.

\section{Data}

We use daily observations of CDS mid-quotes, bond yields, equity prices and option implied volatilities for Marks \& Spencer from January 2006 until July 2009. CDS bid and ask quotes are obtained from GFI, a market leader in OTC credit derivatives trading. We select senior unsecured CDS contracts with the 5-year maturity as they are the most liquid. We derive credit spreads from outstanding corporate bonds. Then, we construct synthetic 5-year credit spreads using yields for two bonds (from Bloomberg) with the following characteristics: they are senior unsecured; they have "generic" Bloomberg mid-market prices; they are not floating-rate and do not have embedded options or any special features; one bond has a maturity below 5 years while the other has a maturity above 5 years. From Bloomberg we also obtain 5-year swap rates which we use as a proxy for the risk free rate (see also Houweling and Vorst, 2005).

In the next step we employ the CreditGrades structural model to estimate the 5-year equity implied spreads. ${ }^{3}$ The following inputs are needed to implement the model: daily series of stock prices and market capitalizations; accounting data on short-term and long-term liabilities, minority interest, preferred shares (all from Bloomberg). We also need the mean global recovery rate $\bar{L}$ and its standard deviation $\delta$; the recovery rate of the senior unsecured debt of the company $R$; the annualized equity volatility $\sigma_{S}$ and the 5-year risk-free interest rate $r$.

For $\bar{L}$ and $\delta$ we take the estimated values of 0.5 and 0.3 , respectively, as reported in the CreditGrades Technical Document. For the recovery rate $R$ we use the value of 0.326 , which is the Moody's average historical recovery rate on senior unsecured debt over the period 19822009 (see Moody's, 2011). As an estimate of the equity volatility $\sigma_{S}$, we employ a 40-day moving average of past equity stock returns (to be consistent with the 2-month maturity used to compute option implied volatilities for the estimation of the 5-year option implied spreads). The

\footnotetext{
${ }^{3}$ Recent studies that have employed this model are Yu (2006) and Avino et al. (2013). Details on the model's implementation can be found in the CreditGrades Technical Document published by RiskMetrics (2002).
} 
latter are computed by using a modified version of the CreditGrades model as described in Cao et al. (2011). To determine option implied spreads, we use Bloomberg's daily implied volatilities for the 2-month equity ATM (at-the-money) put options.

\section{Methodology}

The first step of our analysis is to check for the presence of unit roots in the four series of spreads. If the series are I(1), we can use a vector error correction model to analyse whether the $\mathrm{CDS}$, bond, equity and option markets share a long run equilibrium captured by cointegrating relations. The general model to describe changes in credit spreads for the four markets is given below:

$$
\Delta Y_{t}=\alpha+\Lambda C E_{t-1}+\sum_{k=1}^{p} \beta_{k} \Delta Y_{t-k}+\varepsilon_{t}
$$

where,

$$
\begin{aligned}
& Y_{t}=\left(C D S_{t}, B C S_{t}, E I S_{t}, O I S_{t}\right)^{\prime}, \quad \alpha=\left(\alpha_{1}, \alpha_{2}, \alpha_{3}, \alpha_{4}\right)^{\prime}, \quad C E_{t}=\left(C E_{1, t}, C E_{2, t}, C E_{3, t}\right)^{\prime}, \\
& \Lambda=\left(\lambda_{i j}\right)_{i=1, \ldots, 4, j=1, . ., 3}, \quad \beta_{k}=\left(\beta_{k, i j}\right)_{i=1, . .4, j=1, . ., 4}, k=1, \ldots, p, \quad \varepsilon_{t}=\left(\varepsilon_{1, t}, \varepsilon_{2, t}, \varepsilon_{3, t}, \varepsilon_{4, t}\right)^{\prime}
\end{aligned}
$$

where $C D S, B C S, E I S$ and $O I S$ indicate CDS mid-quotes, bond credit spreads, equity implied spreads and option implied spreads, respectively. The cointegrating equations are defined as:

$$
\begin{aligned}
& C E_{1, t}=C D S_{t}-\phi_{11}-\phi_{21} O I S_{t} \\
& C E_{2, t}=B C S_{t}-\phi_{12}-\phi_{22} O I S_{t} \\
& C E_{3, t}=E I S_{t}-\phi_{13}-\phi_{23} O I S_{t},
\end{aligned}
$$

We then apply a 4-variate GARCH model to the VECM innovations as follows:

$\varepsilon_{t} \mid \Omega_{t-1} \sim N\left(0, H_{t}\right)$

where $\Omega_{t-1}$ is the information set at time $t-1$. Our analysis is based on the BEKK specification of the GARCH model of Engle and Kroner (1995): 
$H_{t}=C^{\prime} C+A^{\prime}\left(\varepsilon_{t-1} \varepsilon_{t-1}^{\prime}\right) A+B^{\prime} H_{t-1} B$

where $H_{t}=\left(\begin{array}{ccc}h_{11, t} & \ldots & h_{14, t} \\ \vdots & \ddots & \vdots \\ h_{41, t} & \cdots & h_{44, t}\end{array}\right), C=\left(\begin{array}{ccc}c_{11} & \ldots & c_{14} \\ \vdots & \ddots & \vdots \\ 0 & \cdots & c_{44}\end{array}\right), A=\left(\begin{array}{ccc}a_{11} & \ldots & a_{14} \\ \vdots & \ddots & \vdots \\ a_{41} & \cdots & a_{44}\end{array}\right), B=\left(\begin{array}{ccc}b_{11} & \ldots & b_{14} \\ \vdots & \ddots & \vdots \\ b_{41} & \cdots & b_{44}\end{array}\right)$.

The above model lends itself well to a derivation of a time varying price discovery measure. The original version of Hasbrouck (1995)'s measure, the "information share" is static. The measure consists of an upper and lower bounds. These are derived by first estimating the Cholesky factorization of the covariance matrix $(C)$ of the VECM residuals in our system of $n=4$ variables in order to eliminate contemporaneous correlation:

$C=M M^{\prime}$

where $M$ is a lower triangular matrix with elements $M=\left(m_{i j}\right)_{i, j=1, \ldots, n}$. The upper and lower bounds of the IS measure for each market $k$, with $1 \leq k \leq n$ are given in equations (8) and (9):

$$
\begin{aligned}
& I S(U B)_{k}=\frac{\left[\sum_{i=1}^{n} \lambda_{i}^{\perp} m_{i 1}\right]^{2}}{\left[\sum_{i=1}^{n} \lambda_{i}^{\perp} m_{i 1}\right]^{2}+\left[\sum_{i=2}^{n} \lambda_{i}^{\perp} m_{i 2}\right]^{2}+\ldots+\left[\lambda_{n}^{\perp} m_{n n}\right]^{2}} \\
& I S(L B)_{k}=\frac{\left[\lambda_{n}^{\perp} m_{n n}\right]^{2}}{\left[\sum_{i=1}^{n} \lambda_{i}^{\perp} m_{i 1}\right]^{2}+\left[\sum_{i=2}^{n} \lambda_{i}^{\perp} m_{i 2}\right]^{2}+\ldots+\left[\lambda_{n}^{\perp} m_{n n}\right]^{2}}
\end{aligned}
$$

with $\left(\lambda_{i}^{\perp}\right)$ the orthogonal vector to the error correction coefficient matrix $\Lambda$ in the VECM. ${ }^{4}$ Baillie et al. (2002) suggest that the mid-point of the bounds gives a reasonable estimate of price discovery. In the analysis below, IS will refer to the bounds' mid-point.

As the IS is a function of the volatilities and covariances of the error terms in the VECM, we can produce a time dependent (daily) IS by replacing the time-invariant covariance matrix $C$ used for

\footnotetext{
${ }^{4}$ Equation (8) is computed when the ordering of the markets in the VECM is such that market $k$ is the first one whilst (9) is computed when the ordering of the markets has market $k$ in the last position.
} 
the calculation of IS measures with its conditional counterpart obtained with (6), under the assumption that the $\lambda_{i}^{\perp}$ 's are stable over the whole period.

We apply the above IS measure to a simple forecasting exercise. We consider a VAR model for the four series above, but where we replace the explanatory variables (which are past changes in the spreads) with cross-products of the changes in credit spreads and the IS measures of the corresponding markets, namely: $I S_{C D S, t-1} \cdot \Delta C D S_{t-1}, I S_{B C S, t-1} \cdot \Delta B C S_{t-1}, I S_{E I S, t-1} \cdot \triangle E I S_{t-1}$ and $I S_{O I S, t-1} \cdot \Delta O I S_{t-1}$. The rationale behind this approach is that if a market reveals a large amount of information at any point in time then it should have stronger forecasting power at that time. Looking at it differently, the auto-regression parameters can be thought of as being time-varying and dependent on each market's information share. In our analysis we will compare the forecasting power of the above model with the forecasting ability of a standard VAR model. We use a rolling window of length 200 and we compare the mean squared error of the forecasts. ${ }^{5}$

\section{Results}

We split our sample into a pre-crisis sub-sample, which starts in January 2006 and ends in July 2007, and a crisis sub-sample that begins in August 2007 and lasts until the end of the observation period in July 2009. We set August $1^{\text {st }}, 2007$ as the starting time of the crisis because the cost of insurance against default for several companies doubled in that month.

Descriptive statistics of the four series of credit spreads are shown in Table 1 (Panel A). Average spread changes across the four markets and their volatilities are higher during the subprime crisis. The kurtosis and skewness measures indicate that the distributions of CDS changes for the four markets are not normal regardless of the sub-period considered. The four series of spread changes are autocorrelated and show strong ARCH effects in each sub-period. The spread levels are all non-stationary and first differencing makes them stationary. The Johansen trace test

\footnotetext{
${ }^{5}$ It is to be noted that this is a not a true out-of-sample forecasting exercise as for the estimation of the time varying IS measure we used the parameters of the VECM and BEKK models estimated over the whole period. These parameters could have been estimated on a rolling basis, using only the observations in the rolling window, but given that it has length 200 the estimates would have been affected by small sample bias.
} 
statistics $^{6}$ shows that the four series of spreads are cointegrated variables which share one common factor. As suggested by the Akaike criterion, we select two lags for the implementation of the Johansen trace test and the VECM in equations (1)-(4).

Panel B of Table 1 reports the (unconditional) IS measure for each market during each subperiod. The results show that in the pre-crisis period the credit risk price discovery for Marks \& Spencer is dominated by the equity implied spreads which account for $86 \%$ of the total price discovery, whereas during the subprime crisis the option implied spreads lead with $48 \%$ of price discovery, followed by the equity implied spreads (19\%), bond (18\%) and CDS spreads (16\%).

Using the method described above, we compute the daily time-varying IS measure for each of the markets based on the BEKK GARCH specification ${ }^{7}$ for the error terms in our VECM, and present these in Figure 1. The results highlight the variability of the price discovery measure as it allows us to capture a greater variety of patterns than an analysis based on the static IS measure shown in Table 1. Indeed, the period preceding the crisis is mainly characterised by the dominant role of the equity market in line with the price discovery results discussed above. However, we can see that in the first part of the crisis period the equity market still plays the leading role in price discovery until June 23, 2008. Then, in the heat of the crisis, immediately before and also after the default of Lehman Brothers, the option market takes a clear lead. Finally, from the second quarter of 2009, when the crisis subsides and stock markets start to recover, the equity market bounces back to its pre-crisis dominant role.

Panel C of Table 1 reports the mean squared errors for both a VAR model estimated for the four credit spreads and its augmented version which replaces the lags of the changes of the credit spreads with the cross-products of each variable's changes and its corresponding conditional IS measure. Our results show that accounting for time variation in price discovery increases the forecasting power of the VAR model as the mean squared error values for the augmented regressions are always lower than those of the standard VAR.

\section{Conclusions}

\footnotetext{
${ }^{6}$ These are 166.30 for no cointegration, 54.10, 16.70 and 1.89 for at most 1,2 and 3 cointegrating equations, respectiely, computed over the whole sample.

${ }^{7}$ The GARCH model coefficient estimates are available on request.
} 
In this paper we derive a dynamic price discovery measure that offers the opportunity to represent, in a clear and intuitive way, the time varying behaviour of the information flow among markets. In particular, we look at the price formation mechanism in the credit spreads obtained from the CDS, bond, stock and option markets. We show, with a case study, how multivariate GARCH models can be used to compute a time-varying version of Hasbrouck (1995)'s price discovery indicator. Our results highlight the variability of the information flow across markets and confirm its high sensitivity to changing market conditions. Additionally, we present a simple example of how this time-varying measure can be used to improve the forecasting power of a standard econometric model.

\section{References}

Acharya, V.V., Johnson, T.C., 2007. Insider trading in credit derivatives. Journal of Financial Economics 84, 110-141.

Avino, D., Lazar, E., Varotto, S., 2013. Price discovery of credit spreads in tranquil and crisis periods. International Review of Financial Analysis, forthcoming.

Bai, J., Collin-Dufresne, P., 2011. The CDS-bond basis during the financial crisis of 2007-2009. Working Paper. Available at SSRN: http://dx.doi.org/10.2139/ssrn.1785756

Baillie, R.T., Booth, G.G., Tse, Y., Zabotina, T., 2002. Price discovery and common factor models. Journal of Financial Markets 5, 309-321.

Berndt, A., Ostrovnaya, A., 2008. Do equity markets favour credit market news over options market news? Working Paper, Carnegie Mellon University.

Blanco, F., Brennan, S., Marsh, I.W., 2005. An empirical analysis of the dynamic relationship between investment grade bonds and credit default swaps. Journal of Finance 60, 2255-2281.

Cao, C., Yu, F., Zhong, Z., 2011. Pricing credit default swaps with option-implied volatility. Financial Analysts Journal 67, 67-76.

RiskMetrics Group, 2002. CreditGrades technical document.

Engle, R., Kroner, K., 1995. Multivariate simultaneous generalized ARCH. Econometric Theory $11,122-150$.

Forte, S., Peña, J.I., 2009. Credit spreads: An empirical analysis on the informational content of stocks, bonds, and CDS. Journal of Banking and Finance 33, 2013-2025 
Hasbrouck, J., 1995. One security, many markets: determining the contributions to price discovery. Journal of Finance 50, 1175-1199.

Houweling, P., Vorst, T., 2005. Pricing default swaps: empirical evidence. Journal of International Money and Finance 24, 1200-1225.

Longstaff, F.A., Mithal, S., Neis, E., 2003. The credit-default swap market: is credit protection priced correctly? Working Paper, University of California, Los Angeles.

Moody’s, 2011. Corporate default and recovery rates, 1920-2010. Moody’s Investor Service.

Norden, L., Weber, M., 2009. The co-movement of credit default swap, bond and stock markets: an empirical analysis. European Financial Management 15, 529-562.

Yu, F., 2006. How profitable is capital structure arbitrage? Financial Analysts Journal 62, 47-62.

Zhu, H., 2004. An empirical comparison of credit spreads between the bond market and the credit default swap market. Journal of Financial Services Research 29, 211-235. 
Table 1. Descriptive statistics, cointegration and price discovery for Marks \& Spencer Plc

This table reports descriptive statistics (Panel A) for the time series of Marks \& Spencer's daily credit spread changes for the CDS, bond, equity and option markets during the period January 2006 - December 2012. Panel B reports the midpoint of the unconditional information share (Hasbrouck, 1995) for each market. Statistics are shown for three sub-periods: the pre-crisis period (January 2006 - July 2007), the subprime crisis (August 2007 - July 2009) and the whole sample (January 2006 - July 2009). The optimal number of lags is chosen according to the Akaike criterion. *, ** and $* * *$ indicate significance at the $10 \%, 5 \%$ and $1 \%$ level, respectively. Panel $\mathrm{C}$ reports the mean squared error for individual forecasts of the credit spreads of each market using a VAR system of equations and a VAR system where the explanatory variables are cross-products of each market's information share (Hasbrouck, 1995) and spread changes, based on a rolling window of length 200. The VARs are based on daily credit spread changes for the CDS, bond, equity and option markets.

\begin{tabular}{|c|c|c|c|c|c|c|c|c|c|c|c|c|}
\hline & \multicolumn{3}{|c|}{$\mathrm{CDS}$} & \multicolumn{3}{|c|}{ Bond } & \multicolumn{3}{|c|}{ Equity } & \multicolumn{3}{|c|}{ Option } \\
\hline & $\begin{array}{l}\text { Pre- } \\
\text { crisis }\end{array}$ & $\begin{array}{c}\text { Subprime } \\
\text { crisis }\end{array}$ & $\begin{array}{c}\text { Whole } \\
\text { sample }\end{array}$ & $\begin{array}{l}\text { Pre- } \\
\text { crisis }\end{array}$ & $\begin{array}{c}\text { Subprime } \\
\text { crisis }\end{array}$ & $\begin{array}{l}\text { Whole } \\
\text { sample }\end{array}$ & $\begin{array}{l}\text { Pre- } \\
\text { crisis }\end{array}$ & $\begin{array}{c}\text { Subprime } \\
\text { crisis }\end{array}$ & $\begin{array}{c}\text { Whole } \\
\text { sample }\end{array}$ & $\begin{array}{l}\text { Pre- } \\
\text { crisis }\end{array}$ & $\begin{array}{c}\text { Subprime } \\
\text { crisis }\end{array}$ & $\begin{array}{c}\text { Whole } \\
\text { sample }\end{array}$ \\
\hline \multicolumn{13}{|l|}{ A. Summary Statistics } \\
\hline Mean & 0.05 & 0.07 & 0.07 & -0.05 & 0.32 & 0.16 & 0.00 & 0.02 & 0.01 & 0.00 & 0.05 & 0.03 \\
\hline Std. Deviation & 1.86 & 14.48 & 10.95 & 1.25 & 9.10 & 6.88 & 0.05 & 63.94 & 48.0 & 0.28 & 63.69 & 48.0 \\
\hline Skewness & 3.02 & -0.14 & -0.17 & 0.20 & 3.53 & 4.66 & -0.84 & 0.47 & 0.63 & -0.30 & 0.19 & 0.25 \\
\hline Kurtosis & 38.53 & 5.90 & 10.19 & 4.94 & 42.85 & 74.1 & 39.10 & 130.3 & 231.1 & 48.46 & 22.44 & 39.79 \\
\hline $\mathrm{Q}(16)$ & 15.32 & $38.38 * * *$ & $65.81 * * *$ & $31.50 * *$ & $59.25 * * *$ & $102.5 * * *$ & $55.20 * * *$ & 4.04 & 7.09 & $86.38 * * *$ & $77.85 * * *$ & $137.1 * * *$ \\
\hline ARCH(16) LM Test & $234.2 * * *$ & $72.31 * * *$ & $183.5 * * *$ & $47.74 * * *$ & $35.90 * * *$ & $69.93 * * *$ & $39.33 * * *$ & 0.32 & 0.11 & 9.65 & $259.6 * * *$ & $475.0 * * *$ \\
\hline ADF (on levels) & -0.31 & -1.71 & -1.24 & -2.37 & -1.47 & -1.24 & -2.05 & -2.19 & -2.46 & -2.38 & -1.75 & -1.62 \\
\hline
\end{tabular}

\section{B. Information Share of Hasbrouck (1995)}

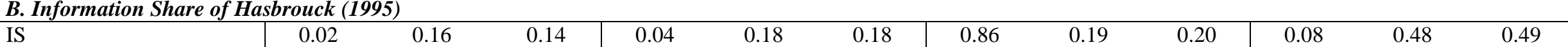

C. Mean squared error of forecasts

VAR

VAR with cross-products

376.36

\begin{tabular}{l}
366.13 \\
\hline
\end{tabular}

213.60

153.78

8140.14

5676.25

4754.22 
Figure 1. Time-varying price discovery measure for Marks and Spencer

The Figure shows the daily midpoint of the conditional information share (IS) for the equity and option markets (upper panel) and the CDS and bond markets (lower panel) for Marks \& Spencer Plc.

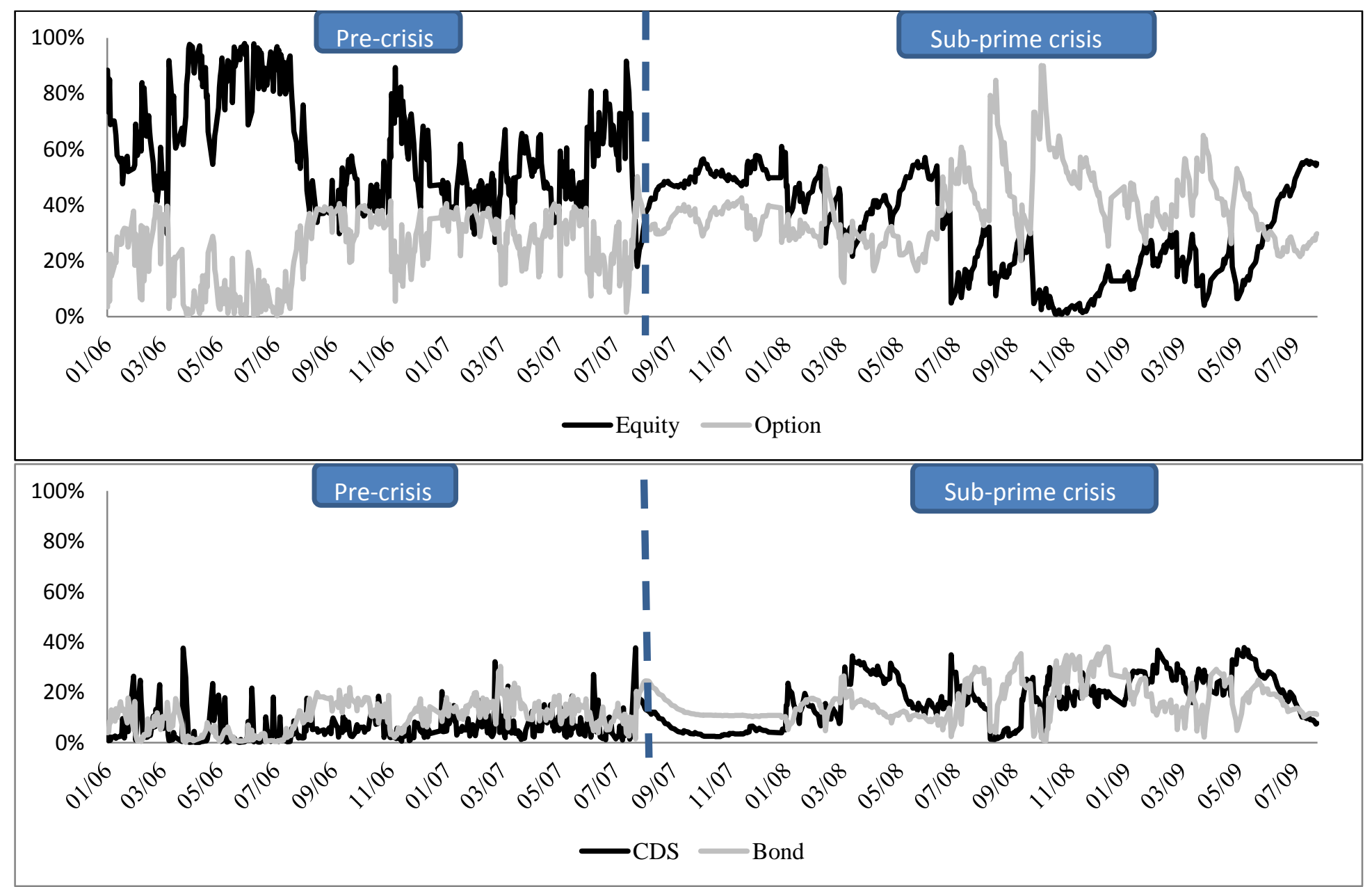

